Vol. 24 N.1 de 2021 ISSN: 1516-8182

Recebimento: 08/11/2020

Aceite: $15 / 01 / 2021$

DOI: 10.25059/2527-2594/retratosdeassentamentos/2021.v24i1.487

\title{
Povos indígenas: conflito entre o direito à terra e o apro- veitamento mineral por não índios
}

\author{
Mara Cristina Maia da Silva ${ }^{1}$ \\ Hildebrando Herrmann ${ }^{2}$
}

Resumo: O artigo faz um esboço da geopolítica de Roraima tendo como objetivo central mostrar os fatores responsáveis pelos processos de configuração do Estado no tocante à ótica da sua organização espacial, política e econômica de modo que o leitor possa identificar e refletir com relação aos diferentes elementos constitutivos que ocorrem na sociedade roraimense, principalmente com relação aos interesses dominantes e, consequentemente, aos conflitos gerados entre índios e não índios concernentes à exploração de minérios em Terras Indígenas.

Palavras-Chave: Roraima. Indígenas. Mineração. Conflitos. Agenda Política.

INDIGENOUS PEOPLES: CONFLICT BETWEEN THE RIGHT TO LAND AND MINERAL EXPLOITATION BY NON-INDIANS

ABSTRACT: The paper outlines the geopolitics of Roraima State with the main objective to shed light on the factors responsible for the processes through which the State is arranged in terms of its spatial, political, and economic organization. Therefore, the reader should be able to identify the different elements that constitute Roraima's society and reflect upon them, especially in relation to the State's dominant interests and, consequently, to the conflicts between indigenous and non-indigenous people produced by the exploration and exploitation of minerals within Indigenous Lands. Finally, the paper summarizes, in the light of the government's political agenda, the mechanisms of Roraima's geopolitics, as well as underlying economic interests and conflicts involving Indigenous Lands and the illegal exploitation of minerals.

Keywords: Roraima. Indigenous people. Mining., Conflicts. Political Agenda.

\footnotetext{
${ }^{1}$ Doutoranda em desenvolvimento Territorial e Meio Ambiente - Universidade de Araraquara- SP. E-mail: drahmara@ gmail.com

${ }^{2}$ Docente no programa de Pós-Graduação em Desenvolvimento Territorial e Meio Ambiente (Mestrado e Doutorado).

E-mail: herrmann@ige.unicamp.br
} 


\section{Caracterização do Estado de Roraima}

Roraima situa-se no extremo norte do Brasil. Desde o começo do século XVI, Roraima tem sido um espaço muito disputado por causa de suas abundantes reservas minerais. Etimologicamente a palavra Roraima se origina do idioma indígena ianomâmi, "roroi" é o nome dado à cor verde e, ímã que dizer serra, monte, ou seja, serra verde, paisagem que natural de Roraima.

Roraima é um Estado com a presença de diversas etnias indígenas e grandes conflitos gerados por demarcação de terras indígenas, além de conflitos ligados ao preconceito étnico e problemas socioeconômicos. Porém, Roraima não vive apenas de problemas. Existe em Roraima várias empresas que comandam o turismo no estado. As TI's Raposa Serra do Sol é a primeira do Estado e a quarta do país a receber visitantes e investir no etnoturismo, por exemplo. ${ }^{3}$ Oferece aos turistas atrativos naturais e culturais da região.

O Estado de Roraima situa-se acima da linha do equador e faz fronteiras ao norte e noroeste com o estado do Amazonas ao sul e oeste, à leste com a Guiana e ao sul com o estado do Pará. Situa-se no Planalto das Guianas e faz fronteira com a Venezuela e Guiana. Roraima tem aproximadamente 224 mil quilômetros quadrados, sendo, porém, o estado menos populoso do Brasil. Segundo dados do $\mathrm{IBGE}^{4} \mathrm{o}$ Estado de Roraima consta atualmente com uma estimativa populacional de631 mil habitantes (2020). A capital de Roraima é Boa Vista e possui cerca de 420 mil habitantes.

No que refere aos aspectos naturais, Roraima é formada por florestas e campos/ savanas. As florestas são divididas em: floresta tropical, densa e campirana, sendo que a floresta tropical densa cobre grande parte do lado oeste e sudeste do Estado. Quanto aos componentes abióticos, pode-se ressaltar as características do componente água uma vez que o estado possui uma extensa rede hidrográfica (nem todos navegáveis, com exceção do Rio Branco), principalmente pertencente à bacia do rio amazonas e com rios perenes. Junte-se também a isso, as características do componente abiótico relativo ao clima e ao solo roraimense.

Com relação ao aspecto climático, observa-se que a o clima que predomina em Roraima é o equatorial, quente e úmido. O índice pluviométrico (chuvas) é elevado, com média de $2.000 \mathrm{~mm} / \mathrm{ano}$. A temperatura média anual é de $24^{\circ} \mathrm{C}$. Já com relação ao relevo de Roraima ${ }^{5}$ é composto pelas seguintes formações:

\footnotetext{
${ }^{3}$ Folha Web Em 21/02/2020 às 03:30. Disponível em: https://folhabv.com.br/noticia/CIDADES/Capital/Terra-Indigena-abre-as-portas-para-o-turismo-em-Roraima/62945 Acesso: Maio de 2021.

${ }^{4}$ Instituto Brasileiro de Geografia e Estatística. Disponível em: https://cidades.ibge.gov.br/brasil/rr/panorama . Acesso: Março de 2021.

${ }^{5}$ Geografia de Roraima. Disponível em: < https://www.infoescola.com/geografia/geografia-de-roraima/>Acesso: Março de 2021.
} 
- Pediplano Rio branco;

- Elevações com altitude de até 400 metros de altitude como é o caso da Serra Grande, serrada Lua e serra da Batata;

- Elevações de até 2000 metros (dois mil) - Cordilheira de Pacaraima;

- Elevações de até 3000 metros (três mil) - Monte Roraima.

\section{Verifica-se desta publicação que:}

No Planalto Sedimentar da Guiana, com grandes elevações de topos, geralmente aplainados variam entre 1.000 e quase 3.000 mil metros. Nele está localizado o Monte Roraima. O Planalto do Interflúvio ou AmazonasOrinoco, apresentam vertentes de fortes declividades. Do sudeste para o norte noroeste recebem os nomes de Ucuzeiro e Serra de Pacaraima com 600 a 2.000 metros. A serra do Ucuzeiro tem menos altitude. Estende-se do rio Taraú, no Amazonas às cabeceiras do rio Mucajaí, em Roraima. Suas altitudes variam entre 500 a 800 metros aproximadamente ${ }^{6}$

As savanas de Roraima ${ }^{7}$ conhecidas como "Lavrados", têm como características vegetação gramíneo-lenhosa (capins, ciperáceas e pequenas ervas), além de um estrato arbóreo-arbustivo de pouca densidade e baixo/médio porte. Elas encontramselocalizadas nas províncias Craton Guianês ou Escudo Guianense.

Com relação aos limites entre floresta e lavrado, Campos (2011) afirma o seguinte:

Os limites entre a floresta e o lavrado estão em constante flutuação ao longo do tempo, influenciados por variações climáticas que ocorrem na escala de dezenas de milhares de anos. Durante estes ciclos, as florestas se expandem nos momentos mais úmidos, enquanto savanas avançam nos períodos mais frio e seco. Mais recentemente, o uso e manejo do fogo pelas populações humanas também contribuiu para a dinâmica da paisagem. Após a última expansão das florestas, as savanas que restaram no interior da Amazônia representam relíquias do passado da paisagem, sendo o Lavrado a maior delas (CAMPOS, p. 17).

No que se refere à questão hídrica, Roraima possui uma extensa hidrografia:

\footnotetext{
${ }^{6}$ Fonte: https://www.infoescola.com/geografia/relevo-de-roraima/. Acesso: Abril de2021.

${ }^{7}$ Fonte: INPA - Instituto Nacional de Pesquisa da Amazônia. Disponível: http://agroeco.inpa.gov.br/reinaldo/RIBarbosa_ ProdCient_Usu_Visitantes/2006Indica\%C3\%A7\%C3\% A3o_UCLavrado_v3.pdf. Acesso: Março 2021.
} 
A rede hidrográfica de Roraima faz parte da Bacia do Rio Amazonas, é o rio mais importante, responsável pela formação de uma bacia regional. O Rio Branco é influenciado pelo índice de chuvas, o que mostra o seu maior volume nos meses de abril a setembro época do inverno roraimense e de outubro a março enfrenta seu período mais seco ${ }^{8}$

Em época de verão escaldante formam-se grandes quantidades de praias, tornando-se ideias para o turismo e lazer, além, disso, existem rios de corredeiras localizados ao norte do Estado, que proporcionam visitas turísticas ${ }^{9}$. Os maiores rios de Roraima são Uraricoera e Tacutu que juntos dão origem ao Rio Branco, Amajari, Parimé, Maú, Surumu e Cotingo.

Com relação às características dos solos presentes no estado de Roraima ${ }^{10}$ existem várias características na sua formação. Anjos et al. (2012) diz que "a classificação de solos promove a comunicação de informações, facilitando a compreensão da complexidade dos solos e sistemas naturais". Segue abaixo as principais características do solo roraimense: ${ }^{11}$

- Latossolos Amarelos - São solos minerais, entre os horizontes ou camadas quase homogêneas do solo com a profundidade;

- Argissolos Amarelos - São originados principalmente de materiais argilosos ou areno-argiloso. O relevo nas áreas de ocorrência é pouco movimentado favorecendo a mecanização no uso das terras. A principal limitação de uso é a fertilidade normalmente baixa, risco de erosão causada pela diferença de textura superficial e subsuperficial e condições de declividade ${ }^{12}$. Apresentam boas condições físicas de retenção de umidade e boa permeabilidade. Em Roraima são utilizadas principalmente para a pastagem;

- Argissolos Vermelho Amarelos - São solos também desenvolvidos de Grupo de barreiras de rochas cristalinas ou sob influência destas. Apresentam muito baixa fertilidade natural ${ }^{13}$; Os argilosos vermelho-amarelos (PVA) são solos também desenvolvidos do Grupo de Barreiras de rochas cristalinas ou sob influência destas. Apresentam horizonte de acumulação de argila, B textural (Bt), com cores vermelho-

\footnotetext{
${ }^{8}$ Extraído de: Fórum, Mudanças Climáticas e Justiça Socioambiental. Disponível em: https://fmclimaticas.org.br/rio-brancoo-rio-de-roraima/ Acesso: Junho de 2021.

${ }_{9}^{9}$ Extraído do Fórum Mudanças Climáticas e Justiça Socioambiental. Disponível em: < https://fmclimaticas.org.br/rio-brancoo-rio-de-roraima/> Acesso: Maio de 2021.

${ }^{10}$ EMBRAPA. Disponível em: https://www.infoteca.cnptia.embrapa.br/infoteca/bitstream/doc/696253/1/ BP012003solosroraimavaldinar.pdf> Acesso: Abril de 2021.

${ }^{11}$ Fonte: < http://www.iac.sp.gov.br/solossp/pdf/Latossolos.pdf > Acesso: Maio de 2021.

${ }^{12}$ Fonte: Disponível em: https://www.agencia.cnptia.embrapa.br/gestor/solos_tropicais/arvore/CONT000gmzitqc102wx5ok0liq1mq4i6tjgq.html. Acesso: Abril de 2021.

${ }^{13}$ Disponível em: fr.htmlhttps://www.agencia.cnptia.embrapa.br/gestor/territorio_mata_sul_pernambucana/arvore/CONT000gt7eon7k02wx7ha087apz2axe8n > : Abril de 2021.
} 
amareladas devido à presença da mistura dos óxidos de ferro hematita e goethita. ${ }^{14}$

- Planossolos - Ocorrem em áreas de cotas baixas, planas a suave onduladas. São, geralmente, poucos profundos, com horizonte superficial de cores claras e textura arenosa ou média (leve), seguido de um horizonte B plânico (horizonte característico dos planossolos), de textura média, argilosa ou muito argilosa, adensado, pouco permeável, com cores de redução, decorrente de drenagem imperfeita, e responsável pela formação de lençol suspenso temporário. Esses tipos de solo apresentam grandes quantidades de minerais facilmente intemperizáveis, o que lhes confere grande capacidade de fornecer nutrientes às plantas. ${ }^{15}$

- Neossolos Quatzarênicos - Esta classe de solo ocorre em relevo plano ou suave ondulado, apresenta textura arenosa ao longo do perfil e cor amarelada e uniforme abaixo do horizonte $A$, que é ligeiramente escura ${ }^{16}$. São solos essencialmente minerais com sequência de horizontes $\mathrm{A}-\mathrm{C}$, em textura areia ou areia franca, no mínimo até $150 \mathrm{~cm}$ de profundidade. ${ }^{17}$

- Neossolos Quatzarênicos abrangem diversos ambientes climáticos, desde áreas de relevos muito movimentados (ondulados e montanhosos) até as áreas planas, sob a influência do lençol freático.

\section{NAÇões INDÍGENAS E SUA DISTRIBUIÇÃo ESPACIAL NO ESTADO DE RORAIMA}

É fundamental ressaltar a importância dos indígenas na cultura roraimense. Embora ofuscado por um conjunto de preconceitos e de estereótipos, o indígena vem contribuindo muito na cultura e na economia local. Ao contrário das controvérsias midiáticas e outras, os indígenas embora priorizem seus costumes, suas crenças e o bem-estar das suas comunidades, interagem de forma amistosa com a população não indígena e com as diversas culturas existentes em Roraima.

De acordo com dados do Censo Demográfico realizado em 2010 pelo Instituto de Geografia e estatística (IBGE) a capital roraimense possui 60.722 pessoas que se identificam como indígenas, ocupando a $5^{\text {a }}$ posição no ranking dos municípios com maior incidência de população indígena no Estado (IBGE, 2010).

A pobreza e o preconceito sofrido marcam a condição da maioria dos indígenas que vivem nas cidades de Roraima, principalmente na capital- Boa Vista. As famílias dos indígenas geralmente se unem em comunidades nos bairros periféricos. A

\footnotetext{
${ }^{14}$ Extraído de Disponível em: https://www.agencia.cnptia.embrapa.br/gestor/territorio_mata_sul_pernambucana/arvore/ CONT000gt7eon7k02wx7ha087apz2axe8nfr.html\#: :text=Os\%20Argissolos\%20Vermelho\%2DAmarelos\%20(PVA,de\%20 ferro\%20hematita\%20e\%20goethita. Acesso: Maio de 2021.

${ }^{15}$ Ibidem Embrapa

${ }^{16}$ CNPTIA: https://www.agencia.cnptia.embrapa.br/gestor/solos_tropicais/arvore/CONT000gn230xho02wx5ok0liq1mqtarta66. html\#: :text=Ag\%C3\%AAncia\%20Embrapa\%20de\%20Informa\%C3\%A7\%C3\%A3o\%20Tecnol\%C3\%B3gica,A\%2C\%20que\%20 \%C3\%A9\%20ligeiramente\%20escuro. Acesso: Abril de 2021.

${ }^{17}$ Ibidem Embrapa.
} 
ancestralidade e referências dos indígenas sofrem preconceitos de diversas ordens, a ponto de muitos indígenas negarem a origem em suas referências culturais, o que comprometerá, com o passar dos anos, a sua unidade cultural.

Segundo Silva (2009, p. 56): “o contingente de indígenas, está, cada vez mais, presente na população das cidades, que somados às populações já carentes, trazem consequências como o desemprego, falta de planejamento quanto ao desenvolvimento e inchaço nas periferias". O número de indígenas na área urbana de Boa Vista - RR vem aumentando devido o fluxo de imigrantes provenientes das etnias indígenas do lado venezuelano.

De acordo com o Instituto Brasileiro de Geografia e estatística (IBGE- 2019) ${ }^{18}$, Roraima tem o segundo maior número de localidades indígenas do Brasil. Segundo estudo do IBGE das 7.103 localidades indígenas do Brasil 587 estão em Roraima. Segundo matéria da Folha de Boa Vista (2016) ${ }^{19}$ "Roraima é o Estado brasileiro que tem o maior número de indígenas em terras demarcadas com 83,2\%.

De modo geral o Estado de Roraima tem uma população indígena de aproximadamente 49.637 pessoas, divididos em: Yanomami, Ingaricó, Macuxi, Patamona, Taurepang, Waimi-Atroari, Wai-Wai e Wapixana. A maior concentração ${ }^{20}$ indígena fica na localidade de Uiramutã, ocupada por parte das TIs como $88,1 \%$ da população indígena, o município de Normandia com $56,9 \%$, ocupa a segunda posição do ranking, seguida de Pacaraima com 55,4\% e Amajari com 53,8\%. São faladas diversas línguas indígenas: Macuxi, Wapixana, Yanomami, wai-wai, Taurepang, Ingarikó, Ye'kuana, Patamona, Waimiri-Atroari, Sanuma entre outras.

Entre os povos indígenas roraimenses há uma grande diversidade cultural e também linguística. O povo Macuxi faz parte da etnia mais populosa da nação indígena com aproximadamente 30 mil pessoas (macuxis) no Estado de Roraima segundo censo do IBGE 2010. São um povo que além de viver das atividades com a castanha do Pará, o cultivo da banana e o artesanato, também praticam a agricultura, a pesca e a caça de animais para o sustento alimentício da comunidade. A agricultura é de subsistência e representa mais ou menos $50 \%$ de suas atividades econômicas. As roças são preparadas a partir de derrubadas, queima e limpeza para o plantio.

Alguns indígenas com formação no Magistério procuram fortalecer a aprendizagem da língua indígena em algumas comunidades. Com relação à formação educacional, hoje a etnia Yelkuana conta com um professor com o título de mestre. Segundo o site da Universidade Federal de Roraima -UFRR (2017) o

\footnotetext{
${ }^{18}$ Fonte Disponível em: https://g1.globo.com/rr/roraima/noticia/2020/04/24/igbe-registra-mais-de-580-localidadesindigenas-em-roraima.ghtml Acesso: Maio de 2021.

${ }^{19}$ Folha de Boa Vista. Matéria publicada no dia 01/07/2016. Fonte disponível em: https://folhabv.com.br/noticia/CIDADES/Capital/83-2--dos-indigenas-vivem-em-Roraima--diz-IBGE/17782 Acesso: Maio de 2021.

${ }^{20}$ Fonte Disponível em: http://www.hutukara.org/index.php/noticias/476- proporcionalmente-roraima-tem-a-maior-populacao-indigena-do-pais Acesso: Abril de 2021
} 
indígena da etnia Ye’kuano defendeu a dissertação de mestrado com a temática : «Transformações socioespaciais das comunidades indígenas Ye’kuana e Sanumã na região de Auris - Roraima. De acordo com entrevista ao site da Capes- Ministério de Educação (2017), o Professor explica a questão do espaço escolhido para pesquisa : ${ }^{21}$

Duas comunidades indígenas formam o seu objeto de pesquisa : Ashikamau (dos Sanumã subgrupo Yanomami) e Fuduwaadunha (dos Ye'kunana do tronco linguítico Caribe), localizado na região do Aurís, no município de Amajari, na terra indígena Yanomami, estado de Roraima. Essas duas comunidades ocupam o mesmo espaço há mais de meio século, desde a chegada do homem branco à região em 1963. Atualmente, é um polo de atração para moradores de outras comunidades, incluindo comunidades indígenas da Venezuela, Explicou Castro (Brasil, 14.06.2017)

Continuando a sua fala, Castro diz que 'a sedentarização das comunidades indígenas começou a trazer como consequência a escassez dos recursos naturais, como falta de caça, pesca e de solos férteis para as roças, palhas e madeiras' [...] (BRASIL, 2017). Segundo Freitas (2017):

A luta pela educação escolar acompanha a história do movimento indígena de Roraima desde os anos de 1970 [...] [...] O resultado desse momento histórico de luta e resistência foi a criação no ano seguinte do Núcleo de Educação Indígena no âmbito da Secretaria de Educação do Território Federal de Roraima para tratar das políticas educacionais dos povos indígenas (FREITAS, 2017, p. 80-81).

Com essas conquistas nos campos [...] da educação os povos indígenas buscam agora a formação escolarização dos indígenas nas diversas áreas para garantir a autonomia das comunidades (FREITAS, 2017, p. 80). Continuando, Freitas (2017) ressalta :

A experiência do Insikiran com a criação de três cursos específicos (Licenciatura Intercultural, Gestão Territorail Indígena, Gestão em Saúde Coletiva Indígena), mostra a força do movimento indígena em Roraima na conquista dos seus direitos, lucus de emancipação e cidadania e também da complexidade na concepção moriniana [...] [...] as comuinidades indígenas têm a garantia de poder usar suas línguas maternas inserindo seus processos próprios de aprendizagens no contexto escolar. Ou seja, cada povo indígena pode usar sua língua materna e buscar novas formas de conhecimentos e

\footnotetext{
${ }^{21}$ Brasil. Ministério da Educação (14.06.2017) Disponível em: https://www.gov.br/capes/pt-br/assuntos/noticias/bolsista-do-observatorio-da-educacao-e-o-primeiro-mestre-da-etnia-ye-kuana. Acesso: Junho de 2021.
} 
aprendizagens a partir de seu contexto sociocultutal, buscando atender as suas necessidades e demandas oriundas do contato a nossa sociedade, como também da própria dinâmica cultural, integrando a organização social desses povos (FREITAS, 2017, p 80-82).

Ainda nesse contexto se faz necessário destacar que os povos indígenas têm o direito educacional específico e que deve ser respeitado. É fundamental que a educação indígena seja conectada com suas especificidades culturais e com um olhar voltado para uma educação integral e cidadã, ou seja, uma educação descentralizada e diferente da educação, que antes era desenvolvida pela Fundação Nacional do Índio, em 1991 por meio de decreto n 26/91 que passou à coordenação do Ministério da Educação (FREITAS, 2017, p. 83).

Enfim, observa-se que além de cestas, balaios, canoas, objetos da caça e pesca, os indígenas roraimenses também produzem as miçangas para adorno da tribo e para a venda no comércio local, principalmente na cidade de Boa Vista - Capital.

Os Yanomami são os indígenas mais vulneráveis devido às invasões e ataques criminosos constantes de garimpeiros totalmente ilegais, que agem em territórios que possuem proteção ambiental legal e que, por isso mesmo, estão indisponíveis às atividades econômicas - a minerária principalmente. Não esquecendo, porém que os mesmos sofrem com doenças e desnutrição das crianças, cujos males são decorrentes deste contato indesejável.

De acordo com a revista Survival ${ }^{22}$ (Movimento Global pelos Direitos dos Povos Indígenas) faz uma matéria sobre Davi Kopenawa, Líder e Xamã Yanomami. Segundo a referida revista:

Davi tem sido fundamental no processo de aproximar as diversas e distantes comunidades Yanomami. Em 2004, ele fundou a Hutukara, uma associação que defende os direitos do povo Yanomami e desenvolve projetos de proteção da terra, educação e saúde. Atualmente ele é presidente dessa organização. Diz a revista: [...] "a coragem, o espírito combativo e a tenacidade de Davi aparecem em seu nome Yanomami 'Kopenawa' que em sua língua significa vespa. O nome veio a ele durante um sonho xamânico quando os espíritosvespa apareceram diante dele. Este foi o momento em que Davi começou a lutar contra a invasão da terra Yanomami por garimpeiros ilegais nos anos de 1980". Este episódio ficou conhecido como a "corrida do ouro" dizimou grande parte da população Yanomami (SURVIVAL, 2016).

${ }^{22}$ Fonte: Disponível em: https://www.survivalbrasil.org/davibiografia > Acesso: Junho de 2021. 
Segundo a revista Survival (2016) “A Hutukara ${ }^{23}$ também organiza diversos cursos e reuniões para encorajar os jovens e as mulheres Yanomami a participarem de projetos, e a fortalecer os laços entre a cura xamânica e a medicina ocidental". A luta de Davi o levou a muitos países. Ele trabalha desde 1980 na defesa do povo Yanomami conectado com ONG brasileira e com a CCPY (Comissão Próyanomami).

A Survival $(2016)^{24}$ ressalta que "O instituto Socioambiental (ISA), uma das principais organizações no Brasil que trabalham com questões socioambientais, especialmente indígenas, assumiu os projetos da CCPY em 2010 e em estreita colaboração em vários projetos da Hutukara. Nilsson (2008, p. 26) afirma o seguinte: "[...] os Yanomami são considerados ainda "primitivos" no discurso local, o que toma difícil a interpretação de seu momento histórico atual, de franca organização política, com a criação de uma associação representativa forte e atuante, a Hutukura Associação Yanomami”.

Segundo Nilsson (2008) nos povos Yanomami,

Não existe a figura do "tuxaua" a priori, essa forma de liderança foi importada de outros grupos da bacia dos Rios negro e Branco e tem pouco significado no contexto Yanomami. Hoje ele, Davi, (grifo do autor) ganha força como um porta-voz como o mundo exterior, são os não Yanomami que necessitam de ter "aquele que manda" como referência no interior de uma comunidade Yanomami (NILSSON, 2008, p.30).

Segundo fala a Survival do xamã e ativista Yanomami, Davi Kopenawa "os lugares onde índios isolados vivem, pescam, caçam e plantam devem ser protegidos. $\mathrm{O}$ mundo inteiro precisa saber que eles estão em sua floresta e que as autoridades devem respeitar seu direito de viver ali”. (SURVIVAL, 2016). ${ }^{25}$

\section{A riqueza mineral do estado de Roraima}

Com base na Geologia do território roraimense pode-se afirmar com segurança que o Estado é rico em bens minerais, cuja exploração é sequiosamente cobiçada por empresas nacionais e internacionais, tendo em vista o significativo retorno econômico que a atividade trará a seus exploradores. Estima-se em bilhões de dólares o valor das minas existentes em Roraima, especialmente as jazidas de ouro, nióbio, tantalita, diamante, petróleo e carvão

O Estado é rico em jazidas de urânio e nióbio, que é um metal de liga de aço

\footnotetext{
${ }^{23}$ HUTUKURA Termo que significa "a parte do céu do qual nasceu a terra".

${ }^{24}$ Ibidem Survival (2016).

${ }^{25}$ Fonte: https://survivalbrasil.org/povos/yanomami Acesso: Junho de 2021.
} 
especial usado na construção de espaçonaves e materiais de supercondutores. No mercado mundial, segundo o engenheiro de minas Eugênio Pacelli, superintendente do Departamento Nacional de Produção Mineral (DNPM), hoje Agência Nacional de Mimneração - ANM, o nióbio vale muito mais que ouro e diamante. As minas de nióbio estão localizadas nos municípios de Normândia e Pacaraima e a de urânio em Cantá, todas localizadas no Nordeste do Estado, mas que não podem legalmente ser exploradas porque estão jacentes em terras indígenas, especialmente na Raposa Terra do Sol. Quem o proíbe é a legislação brasileira, particularmente o artigo 231 da Constituição Federal, que assim normatiza a atividade em terras indígenas:

"Art. 231 - São reconhecidos aos índios sua organização social, costumes, línguas, crenças e tradições, e os direitos originários sobre as terras que tradicionalmente ocupam, competindo à União demarcá-las, proteger e fazer respeitar todos os seus bens."

$\$ 3^{\circ}$ - O aproveitamento dos recursos hídricos, incluídos os potenciais energéticos, a pesquisa e a lavra das riquezas minerais indígenas só podem ser efetivados com autorização do Congresso Nacional, ouvidas as comunidades afetadas, ficando-lhe assegurada a participação nos resultados da lavra, na forma da lei."

È certo, todavia, que o parágrafo $1^{\circ}$ do artigo 176 da Constituição Federal condiciona a liberação da atividade mineral em áreas protegidas ao cumprimento das exigências da lei a ser editada, conforme se deduz do referido dispositivo constitucional, ora transcrito:

" $\$ 1^{\circ}$ - A pesquisa e a lavra de recursos minerais e o aproveitamento dos potenciais a que se refere o "caput" deste artigo (176) somente poderão ser efetuados mediante autorização ou concessão da União, no interesse nacional por brasileiros ou empresa constituída sob as leis brasileiras e que tenha sua sede e administração no País, na forma da lei, que estabelecerá as condições específicas quando essas atividades se desenvolverem em faixa de fronteira ou em terras indígenas."

Até hoje, todas as tentativas legais de liberação desta atividade em terras indígenas, com exceção de propostas recentes, foram rechaçadas pelo Congresso Nacional, o que não significa que isso seja mantido, haja vista a cupidez das empresas mineradoras, nacionais e internacionais sobre os recursos minerais de Roraima e, principalmente face à posição favorável à mineração em terras indígenas 
manifestadas por alguns Deputados e Senadores na audiência pública realizada pela Comissão de Desenvolvimento Regional e Turismo - CDR.

Das 80 áreas de exploração legal em Roraima (há, na região 376 direitos minerais em processo de licitação, entre os quais, depósito de fosfato, cobre, chumbo, zinco e outros), daquelas áreas, onze se destacam: cinco de diamantes, duas de ouro, uma de urânio, uma de estanho, uma de rochas ornamentais e, principalmente, uma do minério raro, a Tantalita, que serve para a produção de baterias de celular e, da mesma forma que o nióbio, tem alto valor econômico. Outras, de menor valor econômico, podem ser citadas: argila, seixo, areia, brita, etc.

Uma curiosidade a ser pesquisada é a reserva petrolífera da Amazônia. Estimase que a maior reserva de petróleo do mundo é a da Venezuela e o maior poço de petróleo da Venezuela - o Santa Elena - fica na divisa com Roraima, que pode ter, segundo alguns ufanistas pátrios, 70\% da reserva total desta jazida, o que não foi comprovado geologicamente. A segunda maior jazida petrolífera da Venezuela, também segundo alguns, localiza-se na Serra da Neblina, divisa com o Estado do Amazonas. Claro que estas afirmações, segundo o Prof. Dr. Jaime de Agostinho, professor titular da Universidade de Roraima e Presidente da ONG Fundação para o Ecodesenvolvimento da Amazônia, carecem de comprovação científica, mas não são de todo descartáveis, haja vista algumas evidências técnicas comprovadas, que merecem, por isso mesmo, um aprofundamento técnico-metodológico.

O Diretor da Companhia de Pesquisa e Recursos Minerais - CPRM , conhecida como Serviço Geológico Nacional, Jean Flávio Cavalvante afirma que o Serviço executa vários projetos de pesquisa mineral no Estado, três referem-se à água subterrânea, um sobre o potencial de fosfato e outros são sobre levantamento geológico, cujos resultados servem para a indústria mineral e para planejamento de uso e ocupação do solo. Adiantou o agente público que o Estado é rico em ouro, diamante, cobre, tantalita, o radioativo urânio e o nobre nióbio.

O Código de Mineração, Decreto-Lei 227/1967, ainda em vigor, embora obsoleto em alguns dos seus itens, regulamenta o aproveitamento mineral das jazidas descobertas no País, estabelecendo 5 regimes para a exploração e aproveitamento mineral: 1) o de autorização e concessão, que outorga um direito perpétuo ao seu titular; 2) o de licenciamento mineral, regime de dúplice autorização: do MME e da Prefeitura onde se localiza a jazida, para substâncias de uso imediato na construção civil. Trata-se de título precário, com prazo de validade restrito e dirigido ao proprietário do solo; 3) o de monopólio da União para determinadas substâncias minerais (petróleo, gás e minerais nucleares), 4) o de permissão de lavra garimpeira, para substâncias minerais garimpáveis (ouro, diamante, gemas, etc), cuja outorga independe de pesquisas prévias, tampouco, de licença ambiental específica, a não 
ser no caso de cooperativas. Seu titular pode ser pessoa física (o que nos parece equivocado) e jurídica (cooperativa de garimpeiros) e, finalmente 5) o regime de exploração mineral para pessoas jurídicas de direito público, para pequenas obras de engenharia de interesse do órgão e que é outorgado para áreas pequenas e por prazo reduzido.

Não se pode olvidar que a quase totalidade das atividades garimpeiras existentes no território Roraimense são ilegais, posto que desprovidas das competentes licenças administrativas e, principalmente, porque tais jazidas encontram-se em território indigenista, onde a atividade extrativa mineral é terminantemente proibida, nos termos da legislação aplicável à espécie. Ademais, há que se considerar com base na Constituição Federal que a atividade garimpeira deve ser executada, preferencialmente, por cooperativa de garimpeiros e não por pessoas físicas, como é o caso, nos termos do artigo 174 , assim redigido:

“Art. 174 - Como agente normativo e regulamentador (...).”.

“\$3 - O Estado favorecerá a organização da atividade garimpeira em cooperativas, levando em conta a proteção do meio ambiente e a proteção econômica dos garimpeiros."

“ $\$ 4^{\circ}$ - As cooperativas a que se refere o parágrafo anterior terão prioridade na autorização e concessão para pesquisa e lavra dos recursos e jazidas minerais garimpáveis nas áreas onde estejam atuando (regularmente), e naquelas fixadas de acordo com o artigo 21, XXV, na forma da lei."

"Art. 21 - Compete à União:”

"XXV - estabelece as áreas e as condições para o exercício da atividade de garimpagem em forma associativa."

Da leitura destes textos, resta inegável reconhecer que os constituintes de 88 estabeleceram severas restrições ao exercício da atividade garimpeira individual, exatamente porque o garimpeiro, pessoa física, não dispõe de recursos, nem, tampouco, de conhecimentos técnicos para efetuar uma lavra racional, quer do ponto de vista ambiental, quer do ponto de vista social, pois desrespeitam a cultura e os conhecimentos tradicionais dos habitantes do local da jazida, quer porque agridem irreversivelmente a natureza pelo desenvolvimento de uma lavra predatória e inconsequente.

O resultado da omissão do Estado na fiscalização do exercício de uma atividade 
desenvolvida irregularmente por dezenas de milhares de garimpeiros inviabiliza o aproveitamento racional das jazidas minerais e compromete inexoravelmente, num segundo momento, o patrimônio sociocultural dos povos indígenas.

\section{A Geopolítica de Roraima: Resgate da doutrina pertinente, Vis a} VIS COM A SITUAÇÃo NACIONAL E REGIONAL

A organização do espaço roraimense sob a ótica hegemônica encontra-se vinculado a um projeto de organização espacial focado apenas aos interesses econômicos. Lindner (2011, p. 11) fala que "a organização do espaço é percebida através da paisagem do lugar, pois é através dela que se pode visualizar a materialização das ações do passado e do presente, os resquícios históricos da formação e as particularidades de cada lugar".

O engendramento de estruturas socioeconômicas em Roraima é resultado da mobilização de capitais e figuras em torno de seus interesseseconômicos e políticos que sempre fizeram direcionar investimentos em projetos pseudo "ambientais" que nada mais são do que transformar o espaço numa estrutura fundiária centralizada e moldada segundo as necessidades do capital financeiro em detrimento das comunidades indígenas e da sustentabilidade ambiental. Órgãos do governo federal como IBAMA e FUNAI nunca conseguiram empreender soluções. A questão das imposições entre as TIs e UCs das políticas públicas e do poder local configuramse em impactos de ordem econômica e social com relação aos espaços ambientais "protegidos" no território de Roraima.

Todas as estratégias desenvolvimentistas referentes aos espaços roraimenses que vêm se executando ao longo da história são sobreposições hegemônicas que não são viáveis e muito menos interessante para as TIs e as UCs. E por falar de espaços no contexto político econômico e social, Coelho (2009) faz a seguinte afirmação:

[...] Espaços de rivalidades territoriais [...] tanto quanto instrumentos
territoriais e ambientais, unidades que são parte de um processo global
contemporâneo resultante de ações motivadoras / inibidoras e normas
restritivas da expansão humana e econômica ou evidenciador de símbolos
doslimites da exploração e da "proteção ambiental" (COELHO, 2009, p. 77).

O paradigma desenvolvimentista na formação do espaço roraimense é algo muito atual. Percebe-se que as políticas públicas estabelecem limites sociais, políticos e econômicos que atingem negativamente as comunidades indígenas. É na retórica desenvolvimentista que Roraima está inundado de empreendimentos econômicos voltados para o aproveitamento dos recursos minerais e que são responsáveis pelas violações dos direitos das populações atingidas, especialmente das populações 
indígenas.

$\mathrm{Na}$ atual conjuntura econômica, política e social, Roraima passa por mais uma turbulência da velha questão de interesses divergentes a respeito da terra indígena Raposa serra do Sol com a sua homologação desencandeia uma acirrada luta dentro e fora dos tribunais envolvendo o Estado, os latifundiários (arrozeiros), garimpeiros, comunidades indígenas com suas diferentes frentes de luta. De acordo com Fonseca (2016, p. 6) o desenvolvimentismo representa a "expressão da modernidade e traz consigo a utopia de construção".

Lembrando que historicamente após o Território de Roraima se transformar em Estado em 05 de outubro de 1988, verifica-se uma nova fase na política local. O grupo de poder corporificado no estado de Roraima compõe ou compuseram a elite política local, de estreita relação com os interesses econômicos regionais, leiase mineração. Observa-se na política estatal roraimense elites político-partidárias de um grupo fortemente paternalista e assistencialista bastante consistente nas campanhas eleitorais.

Lembrando também que Ottomar de Souza Pinto governou o estado de Roraima, no período que em que era território (1979-1983); como governo nomeado pelo Presidente da República do Brasil, e logo após Roraima se tornar Estado oficial (19912006) por intermédio de eleições, sendo governador do estado por quatro mandatos. Como afirma Lobo Jr. (2008, p. 32) "Ottomar instalou uma política diferente de todos os seus antecessores, ficou conhecido como "governador da paz", pois soube como ninguém arregimentar para o seu lado as lideranças locais". Ottomar era Brigadeiro do quadro de oficiais de engenheiros da Força Aérea Brasileira.

Enfim, pode-se dizer que o cenário geopolítico de Roraima se configura em fatores multifacetados com diferentes atores sociais, principalmente da supremacia branca no papel de protagonistase os indígenas sempre atuando como papel coadjuvante no longo processo histórico. Essa situação permite refletir sobre a questão da territorialidade indígena local na dinâmica das lutas contra a marginalização, invisibilidades, estereótipos e a questão das TIs Raposa Serra do Sol.

Embora os indígenas tenham seus direitos garantidos pela Constituição Federal de 1988, a luta para usufruto da terra ainda é uma problemática pautada na vida dos índios, particularmente de Roraima a que se refere na pesquisa, pois historicamente, pode-se dizer que o movimento indígena de Roraima tem travado uma árdua batalha com relação às imposições de projetos desenvolvimentistas, ameaçando assim as TIs nefastos empreendimentos capitalista. O processo histórico da organização do espaço deRoraima, mostra a edificação forte de uma oligarquia política econômica centralizadora que sempre tratou o índio de forma pejorativa, estereotipada em nome de seus interesses econômicos. 
O incentivo à mineração pelo presidente da República, Jair Bolsonaro e por alguns representantes do poder legislativo federal, fez acender as chamas dos conflitos em Roraima. Como afirma a Pública/newsletter ${ }^{26}(22 / 05 / 2020)$ " [...] o apoio à mineração estimulou as invasões, mas também acordou as lideranças do CIR, que passaram a promover eventos para conscientizar as etnias da Raposa Serra do Sol a não se deixarem encantar por promessas de riqueza fácil”.

Se é certo que o aproveitamento das riquezas existentes no sub solo roraimense pode significar a redenção do Estado, não se pode esquecer, por outro lado, que ele mal regulamentado por decisões apressadas e sem respaldo técnico-científico, pode comprometer inexoravelmente a natureza e as nações indígenas da região.

\section{REFERÊNCIAS}

ANJOS, L. H. C. dos; JACOMINE, P. K. T.; SANTOS, H. G. dos. OLIVEIRA, V.i Á. de. OLIVEIRA, J. B. de. Sistema Brasileiro de Classificação de Solos. In: KER, J. C. et al (Ed.). Pedologia: Fundamentos. Viçosa: SBCS, 2012. Cap. 8. p. 303-343.

BRASIL. Ministério da Educação (14.06.2017) < https://www.gov.br/capes/pt-br/ assuntos/noticias/bolsista-do-observatorio-da-educacao-e-o-primeiro-mestre-daetnia-ye-kuana> Acesso: Junho de 2021.

CAMPOS, Ciro (org). Diversidade Socioambiental de Roraima. Subsídios para debater o futuro sustentável da região. São Paulo: Instituto Socioambiental, 2011.

COELHO, Maria Célia Nunes (et al). Unidades de Conservação: Populações, Recursos e Territórios, Abordagens da Geografia e da Ecologia Política. In: GUERRA, A. J. T. e COELHO, M. C. N. (Org). Unidades de Conservação: abordagens e características geográficas. Rio de Janeiro: Bertrand Brasil, 2009.

FREITAS, Marcos Antonio Braga de. Insikiran: da política indígena à institucionalização da educação superior / Marcos Antonio Braga de Freitas. Tese (Doutorado em Sociedade e Cultura na Amazônia) - Universidade Federal do Amazonas, 2017.

FOLHA WEB Em 21/02/2020 às 03:30. Disponível em: < https://folhabv.com.br/ noticia/CIDADES/Capital/Terra-Indigena-abre-as-portas-para-o-turismo-emRoraima/62945 Acesso: Maio de 2021.

${ }^{26}$ Ibidem 20/05/2020 
FONSECA, P. C. D. Desenvolvimentismo não é sinônimo de intervencionismo. Folha de São Paulo, Ilustríssima, 2016.

EMBRAPA - infoteca.cnptia.embrapa.br/infoteca/bitstream/doc/696253/1/ BP012003solosroraimavaldinar.pdf> Acesso: Abril de 2021.

HERRMANN, Hildebrando. Código de Mineração de "A" a "Z". Campinas, SP: Millennium Editora, 2008

INPA- Instituto Nacional de Pesquisa da Amazônia. Disponível em: < http://agroeco. inpa.gov.br/reinaldo/RIBarbosa_ProdCient_Usu_Visitantes/2006Indica\%C3\%A7\%C3\% A3o_UCLavrado_v3.pdf > Acesso: Março 2021.

LINDNER, Michele. A organização do espaço sob o olhar das ruraliades: estudo da paisagem e lugar no município de São João do Polêsine, Rio Grande do Sul, Rio Claro; UNESP, 2011. Tese (Doutorado em Geografia) - Instituto de Geociências e Ciências Exatas, Universidade Estadual Paulista, 2011.

NILSSON, Maurice Siji Tomioka. Organização indígena Yanomami: das ameaças ao seu território à representação política numa sociedade sem estado. Agrária., São Paulo, 2008.

SILVA, Kalina Vanderlei; SILVA, Maciel Henrique. Dicionário de Conceitos Históricos. 2. ed. 2 reimpressão. São Paulo: Contexto, 2009. 